\title{
The Wind Energy Production Tax Credit as an Alternative to a Carbon Tax
}

\author{
By Jay Sher
}

This paper attempts to determine an optimal level for the wind energy production tax credit based on the carbon dioxide reduction potential of wind energy. The optimal level is calculated using a conservative value for the social cost of carbon and an upper bound for the carbon dioxide reduction potential of wind energy. Even under the most efficient wind energy operation conditions, the reduction in carbon dioxide is not substantial enough to warrant the current value of the production tax credit. Further study is needed to determine why it is so overvalued.

\section{Introduction}

A variety of subsidies, tax credits, and standards have been put in place to expand the capacity of renewable energy infrastructure and, more specifically, wind energy. These subsidies can be viewed as an alternative to a carbon tax, reducing carbon dioxide emissions within the scope of power generation. However, the current level of subsidies is higher than necessary to account for a reasonable social cost of carbon dioxide, creating an inefficient market equilibrium. This article first reviews the federal renewable electricity production tax credit (PTC), and provides a snapshot of the growth of the wind energy market at the national level. Next, it presents the reasoning for the subsidies, providing a description of the estimates of the social cost of carbon dioxide. The article then discusses a comparison of the subsidy level to the proposed costs of carbon dioxide and a theoretical carbon diox- ide tax. Lastly, a brief analysis of potential alterations in the level of the subsidies is presented.

\section{The Wind Energy Production Tax Credit}

A variety of subsidies have been implemented at the federal and state levels that target various parts of the deployment of wind energy from infrastructure funding to the sale of energy.

The PTC provides a subsidy on each kilowatt-hour $(\mathrm{kWh})$ produced by qualified renewable technologies. The wind portion of the PTC was originally introduced in 1992 as a $1.5 \mathrm{k} / \mathrm{kWh}$ credit indexed for inflation, which now equals $2.2 \$ / \mathrm{kWh}$ (NC State University 2013). The PTC is not permanent and has been renewed for one-year and two-year periods. It has been allowed to expire on three separate occasions: in 2000, 2002, and 2004. It was then put back in place with a number of other incentives for renewable energy in the Energy Policy Act of 2005, and was renewed once again in the American Recovery and Reinvestment Act of 2009. Most recently, the PTC was set to expire at the end of 2012, but was renewed by the American Taxpayer Relief Act of 2012 that averted the fiscal cliff (NC State University 2013). Although wind energy is only one of many forms of electricity generation covered by the PTC, it accounts for the majority of the credits claimed. According to projections from the Energy Information Administration, $\$ 16$ billion of the $\$ 17$ billion of expected spending on the PTC be- 
tween 2005 and 2015, assuming constant renewal, will go to wind projects (Namovicz 2005).

\section{Wind Energy in the United States}

Wind energy has experienced substantial growth in the United States over the last decade, encouraged by generous subsidies, growth in domestic wind manufacturing, technological changes, and the size and power capacity of individual wind turbines. The industry is still dependent on continued support from government incentives at the federal, state, and local levels. As shown in Figure 1, 2010 was the first year since 2007 that there was not a year-over-year increase in the amount of wind energy added in the United States. The upward growth trend returned in 2011 and 2012, but it may not continue because of uncertainty caused by the last-minute renewal of the PTC.

Wind energy has become the preeminent renewable growth technology in the United States, with 2012 being a record year for capacity additions. In total, nearly 13 gigawatts (GW) of capacity was installed, and over $\$ 25$ billion of the nearly $\$ 73$ billion of total investment in new generation was invested across the market in
2012 (Tracy 2013; Qureshi 2013). Wind accounted for 44 percent of new generating capacity in 2012, outpacing all other generation types, both conventional and renewable, for the first time ever (Qureshi 2013).

The domestic wind energy manufacturing sector has grown considerably since 2004. At that point, there was a single nacelle (the housing for the mechanical parts of a wind turbine) manufacturer with a factory in the United States. There are now nine companies that both sell turbines in the United States and have at least one domestic factory. The expansion of domestic production has also significantly decreased the level of wind turbine component imports and expanded the export market for these components from the United States (Wiser and Bollinger 2011). The uncertainty in the renewal of the PTC at the end of 2012 could lead to some consolidation in the industry if wind turbine component orders decrease.

\section{Carbon Dioxide Pricing Regimes}

A primary reason for the promotion of wind energy is to reduce negative externalities from energy production with conventional fossil fuels. One of these ex-

Figure 1: Annual Wind Energy Capacity Increases

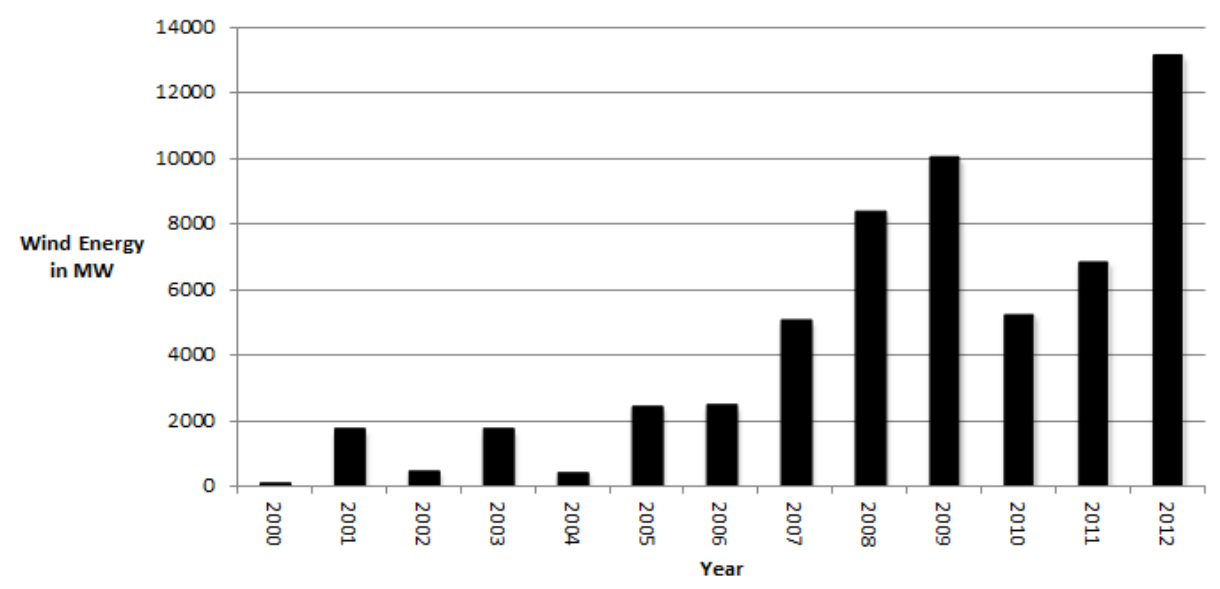

Source: U. S. Department of Energy (as cited in Texas Comptroller of Public Accounts 2008) and American Wind Energy Association 2013. 
ternalities is carbon dioxide emissions linked to climate change. Economists and policy makers have attempted to create a way to attach a price to these externalities because the market may not adequately price them. A number of ways to attach a price to carbon or carbon dioxide have been developed. These alternatives include cap and trade, a direct tax on carbon dioxide, and subsidies for renewable energy sources.

A cap and trade system provides permits for emissions with a set cap level and creates a market for them to be traded. The market for permits creates an incentive for firms with lower marginal costs of abatement to reduce their emissions by a greater amount and then sell their excess permits. The trading of permits creates an opportunity for firms that cannot reduce their emissions as easily-generally older, less efficient plants-to upgrade their plants more slowly and cost effectively by buying extra permits in the short term. The market for permits should theoretically reach an equilibrium that comes close to the true cost of the carbon dioxide externality. Sometimes a minimum price is established because the number of permits originally allocated was too large, which causes the permit value to drop precipitously (Metcalf 2009). Politically, a cap and trade system can be hard to administer, as it may be perceived as an indirect way of taxing citizens who would see the cost downstream in higher electric bills.

A direct tax on carbon dioxide would be based on the amount of carbon dioxide emissions rather than the amount of energy produced. Therefore, the amount of tax paid per unit of energy produced would vary across types of fuel or technology due to their respective emissions levels. The tax could be administered at various levels-anywhere from the importation and processing of the fuel, down to the consumer level. The tax is more efficient the farther upstream it is administered, and it tends to be regressive (Sumner, Bird, and Smith 2009; Belsie 2009).
The imposition of a new tax is a challenge because the effects of climate change have a long time horizon. As a result of the time value of money, citizens typically do not want a cost imposed on them now to reduce possible losses far in the future.

A subsidy regime that favors technologies and generation methods that reduce overall emissions could be viewed as an alternative to a carbon dioxide tax. The level of subsidies could theoretically be tailored to create an equilibrium similar to one reached by imposing a tax at the desired level. The subsidy structure can promote certain types of energy production over others based on their emissions levels. This approach is analogous to the carbon dioxide tax being set at different levels for fuels based on their emissions potential.

It is important to note that subsidies can create inefficient equilibriums if their levels are set too high or too low. If a subsidy level is set too high, it could create an overabundance of certain renewables without adequate infrastructure to integrate them into the grid to produce cost competitive electricity. If the subsidy level is set too low or is underfunded, then its ability to reduce carbon dioxide emissions would be minimal, and it would not act effectively as a carbon tax alternative.

Wind energy seems to be an effective target for subsidies in order to reduce carbon dioxide emissions. The large reductions in the cost of producing wind energy have made it close to, or cost competitive with, conventional fuels, especially in areas with substantial wind resources, like the central United States.

\section{Social Costs of Carbon Dioxide}

The social cost of carbon dioxide is not a single set value. It reflects the cost of the negative externalities created by carbon dioxide emissions, resulting from the possible effects of climate change. Estimates of the cost of carbon dioxide vary widely from low levels of less than $\$ 4$ / tonne of carbon dioxide ( $\mathrm{tCO} 2$ ) to an up- 
per bound over $\$ 400 / \mathrm{tCO} 2$ (Tol 2009). The variability in the estimated cost across studies can be explained by a number of factors, including the uncertainty in the magnitude of temperature increase, individual's rate of time preference or the discount rate, estimations of the aggregate welfare gains and losses globally, regional geographic and climactic differences, and varying models of population and economic growth (Tol 2009). This wide range also makes it challenging to establish a price for carbon dioxide that is directly linked to the costs of mitigating climate change.

There is a reasonable range of costs that can be used from Tol's meta-analysis of the various studies presenting estimates of the cost of carbon dioxide. The data in Tol's meta-analysis are presented for $\$ / \mathrm{tC}$, which is not equivalent to $\$ / \mathrm{tCO} 2$. Carbon dioxide is 3.67 times the weight of carbon alone, therefore the $\$ / \mathrm{tC}$ will be divided by 3.67 to convert it to $\$ / \mathrm{tCO} 2$. These conversions are demonstrated in Table 1. In addition, the unweighted cost values, which are the average of all measures not separated according to the pure rate of time preference, will be used. The mean of the costs is $\$ 105 / \mathrm{tC}$, however, the median is $\$ 29 /$ tC (Tol 2009). The divergence between the mean and median demonstrates that the upper end of the cost estimates is considerably skewed, and the more conservative cost estimates come from the middle of the distribution. In addition, the 9oth percentile measure is utilized as an upper bound and for comparison purposes even though it is fairly skewed.

\section{Calculation of a Theoretical Carbon} Tax

In order to make valid comparisons, the data are standardized to values equivalent to utility scale energy production. The costs will be calculated in \$/ $\mathrm{tCO}_{2}$ because conceptually the emissions from power production would come in this form. The calculations will only include emissions reductions due to power production, not the life cycle costs. The life cycle costs of electricity production include not only the production of electricity, but also the carbon dioxide released by fuel extraction, manufacturing of the plant and equipment, and other steps in the process of transforming fuel into electricity. Life cycle costs present a more holistic comparison between types of generation, but they are beyond the scope of this particular paper. Also, only the PTC value will be used to calculate the theoretical tax since it is administered to utility scale production and at the federal level equally.

The current value of the PTC, as mentioned earlier, is $2.2 \mathrm{~d} / \mathrm{kWh}$ or $\$ 22 /$ MWh. A conventional coal power plant emits about .95tCO2/MWh based on data from 1999 (Department of Energy and Environmental Protection Agency 2000). A coal plant would thus emit 1tCO2/1.05MWh. Wind turbines reduce carbon dioxide emissions by as much as $.54 \mathrm{tCO} 2 / \mathrm{MWh}$ (American Wind Energy Association 2011). Therefore, a wind turbine would reduce emissions by $1 \mathrm{tCO} 2 / 1.84 \mathrm{MWh}$, which would be the maximum value for emissions reductions by wind energy. The actual value varies

Table 1: Estimates of the Social Cost of Carbon

\begin{tabular}{|l|l|l|}
\hline Percentile & Cost in $\$ / \mathrm{tC}$ & Cost in $\$ / \mathrm{tCO}_{2}$ \\
\hline 33rd & $\$ 16$ & $\$ 4.36$ \\
\hline 5 oth & $\$ 29$ & $\$ 7.90$ \\
\hline 67 th & $\$ 67$ & $\$ 18.26$ \\
\hline 9oth & $\$ 243$ & $\$ 66.21$ \\
\hline
\end{tabular}

Source: Tol 2009. 
widely across time, geographic location, and the mixture of generation in the area. The exact amount of carbon dioxide reduction depends on the marginal generation unit that the wind energy is replacing. Furthermore, it is important to note that at certain times, wind energy could actually increase emissions if inefficient peaking turbines are used to deal with intermittent wind production. For wind energy, the value of the subsidy to mitigate $1 \mathrm{tCO} 2$ would be approximately $\$ 40 / \mathrm{tCO}_{2}-$ the result of $\$ 22 / \mathrm{MWh}$ multiplied by $1.84 \mathrm{MWh}$ of wind to mitigate $1 \mathrm{tCO} 2$.

The subsidy from the PTC falls between the 67th and 9oth percentile of the cost of carbon dioxide from the Tol metaanalysis (2009). Even if the $2.2 \mathrm{c} / \mathrm{kWh}$ were alternatively levied as a direct tax on coal, giving it a value of $\$ 23.10 / \mathrm{tCO}_{2}$ ( $\$ 22 / \mathrm{MWh}$ multiplied by $1.05 \mathrm{MWh}$ ), it would still fall within this same range of the meta-analysis. Therefore, the subsidy alone promotes a greater amount of production of wind energy than is efficient based on a market equilibrium price of carbon dioxide at the median of $\$ 7.90 /$ tCO2. In order for the subsidy to equal this value, it would need to be reduced to $.43 \%$ / $\mathrm{kWh}$, which is roughly one-fifth of the current level. As noted above, the PTC is only one of many subsidies for different aspects of the wind energy manufacturing, construction, and energy production process. With all of the subsidies at the federal level and potentially additional subsidies at the state level combined, wind energy could be subsidized well above even the 9oth percentile value of $\$ 66.21 / \mathrm{tCO} 2$.

\section{Conclusion}

There are a number of possible explanations for the subsidy being set well above the economically-desired level. First, it could be that the calculation to set the subsidy assumed a much higher social cost of carbon because of the opinions and beliefs of Congress at the time. It is also possible that the subsidy level is set higher than the equilibrium level to promote the growth of an infant industry and new sector to compete both domestically and globally. Alternatively, the subsidy level could be higher because the actual equilibrium, between the social cost of carbon and the subsidy level, is higher. However, since the subsidy would most likely be calculated using the social cost of carbon, it would be calculated prior to setting the subsidy level and therefore dependent upon that value.

The subsidy also must be viewed in the broader context of multiple types of renewable energy. The PTC covers more than one type of renewable energy. Wind energy currently happens to be considerably more cost-effective than other renewable energy sources, like photovoltaic solar or concentrated solar power. Some of these technologies would not necessarily receive adequate investment to advance technologically without some sort of subsidy. The broader subsidy may have been set at a level that was beneficial to all of the technologies rather than specifically focusing on one. In addition, the relatively simple calculation presented in this article does not include considerations for other technologies under the PTC or variations in wind energy efficiency and production costs across regions.

A further issue with subsidies generally, and the PTC specifically, is their distortionary effects on markets and allocation of investment. While the wind energy industry has grown substantially in the United States with the help of the PTC, it is not necessarily the most efficient allocation of resources, as it may divert funding from other more advantageous emissions reductions efforts and technologies. In addition, the PTC in certain cases may distort specific power markets, causing losses for conventional electricity generation. According to a recent report by The NorthBridge Group, the prevalence of wind energy production at night, when electricity demand is low, is causing negative prices to occur in wholesale electricity markets with a larger concentration of wind energy (Huntowski, Patterson, and 
Schnitzer 2012). Wind producers can offer electricity at a negative price and still turn a profit due to the PTC. At the same time, other sources of energy that cannot ramp down production quickly, such as nuclear and coal plants, must offer their electricity at cost and take a substantial loss. Over time, if these negative prices and the corresponding losses persist, it could cause these base load resources to declare bankruptcy. The loss of these base load resources could undercut the reliability of the electric grid and stifle future capital investment in base load generation.

The social cost of carbon has a wide range of values due to the large amount of uncertainty in the forecasts used to calculate it. Over time, the calcu- lations may become less dispersed and could change considerably as the effects of carbon dioxide emissions become more apparent. If the conservative social cost of carbon estimates averaged by Tol-those closer to the median-are used to calculate the actual value, then the PTC should be reduced by a factor of five. If the equilibrium is actually higher, cutting the subsidy at least in half would bring it closer to the 67 th percentile for the cost of carbon dioxide. The uncertainty in the social cost of carbon dioxide makes setting the subsidy very challenging. However, comparing the subsidy to the social cost of carbon dioxide can shed some light on the market distortions the subsidy may create.

\section{References}

American Wind Energy Association. 2011. "Wind Power and Climate Change.” Accessed November 2011. http://www.awea.org/learnabout/publications/upload/Climate_Change.pdf.

America Wind Energy Association. 2013. "Industry Statistics.” Modified January 01. http://www.awea.org/learnabout/industry_stats/index.cfm.

Belsie, Laurent. 2013. "How Regressive is a Price on Carbon?" Accessed April 2013. http://www.nber.org/digest/jan10/w15239.html.

Department of Energy and Environmental Protection Agency. 2000. "Carbon Dioxide Emissions from the Generation of Electric Power in the United States." Washington, DC: Department of Energy. ftp://ftp.eia.doe.gov/environment/co2emissoo.pdf.

Huntowski, Frank, Aaron Patterson, and Michael Schnitzer. 2012. "Negative Electricity Prices and the Production Tax Credit." Accessed December 2012. http://www. eenews.net/assets/2012/o9/14/document_gw_01.pdf.

Metcalf, Gilbert. 2009. "Market-based Policy Options to Control U.S. Greenhouse Gas Emissions.” Journal of Economic Perspectives 23(2): 5-27.

Namovicz, Chris. 2005. "Production Tax Credit for Renewable Electricity Generation." Issues in Focus, AEO2005. Accessed November 2001. http://www.eia.gov/ oiaf/aeo/otheranalysis/aeo_2005analysispapers/prcreg.html.

North Carolina State University. 2013. "Renewable Electricity Production Tax Credit (PTC).” Accessed March 2013. http://www.dsireusa.org/incentives/incentive. $\mathrm{cfm}$ ? Incentive_Code $=\mathrm{US} 13 \mathrm{~F} \& \mathrm{re}=1 \& \mathrm{ee}=1$.

Summer, Jenny, Lori Bird, and Hilary Smith. 2009. "Carbon Taxes: A Review of Experience and Policy Design Considerations." Washington, DC: Department of Energy. http://www.nrel.gov/docs/fy10osti/47312.pdf.

Texas Comptroller of Public Accounts. 2008. The Energy Report 2008. Accessed November 2011. http://www.window.state.tx.us/specialrpt/energy/.

Tol, Richard S. J. 2009. "The Economic Effects of Climate Change.” Journal of Economic Perspectives 23(2): 29-51. 
Tracy, Ryan. 2013. "Wind-Power Installations Set Record in 2012." The Wall Street Journal, January 30. Accessed February 2013. http://online.wsj.com/article/ SB10001424127887323701904578274230016130030.html.

Qureshi, Rizwan. 2013. "Wind led completed power projects by capacity in 2012." SNL Financial, February 06. Accessed February 2013. http://www.snl.com/interactivex/article.aspx?id=16896392\&KPLT $=6$.

Wiser, Ryan, and Mark Bolinger. 2010. "2010 Wind Technologies Market Report." Washington, DC: Department of Energy. http://www1.eere.energy.gov/wind/ pdfs/51783.pdf.

Jay Sher is a second year Master of Public Administration student in the Trachtenberg School concentrating in regulatory policy. Jay is currently an Energy Industry Analyst at the Federal Energy Regulatory Commission where he focuses on wholesale electricity markets and transmission in the central United States. Jay is a 2011 graduate of The George Washington University with a bachelor of arts degree in political science.

The author would like to thank Kristin Hubing for pushing the author to submit this paper to the journal. He would also like to thank Brandon Kruse for his tireless work managing the editing process, Dr. David Brunori for his comments on this paper, and Dr. Gerald Brock for the discussions that led to the original formulation of the thesis of the paper.

Jay Sher is currently an Energy Industry Analyst with the Federal Energy Regulatory Commission. The opinions and views offered here are his own and not necessarily those of the United States, the Federal Energy Regulatory Commission, the individual Commissioners, or members of the Commission staff. 